\title{
The Incidence of Menstrual Regulation Procedures And Abortion in Bangladesh, 2010
}

\section{By Susheela Singh, Altaf Hossain, Isaac Maddow- Zimet, Hadayeat Ullah Bhuiyan, Michael Vlassoff and Rubina Hussain}

Susheela Singh is vice president for research, Isaac Maddow-Zimet is research assistant, Michael Vlassoff is senior research associate and Rubina

Hussain is research associate-all with the Guttmacher Institute, New York. Altaf Hossain is director, and Hadayeat Ullah

Bhuiyan is training coordinator-both with

the Association for

Prevention of Septic Abortion, Bangladesh (Dhaka).

\begin{abstract}
CONTEXT: Bangladesh is unique in including menstrual regulation (MR) services as part of the government family planning program, despite having a highly restrictive abortion law. The only national estimates of $M R$ and abortion incidence are from a 1995 study, and updated information is needed to inform policies and programs regarding the provision of MR and related reproductive health services.
\end{abstract}

METHODS: Surveys of a nationally representative sample of 670 health facilities that provide MR and postabortion care services and of 151 knowledgeable professionals were conducted in 2010, and MR service statistics of nongovernmental organizations were compiled. Indirect estimation techniques were applied to calculate the incidence and rates of $M R$ and induced abortion.

RESULTS: In 2010, an estimated 647,000 induced abortions were performed in Bangladesh, and 231,400 women were treated for complications of such abortions. Furthermore, an estimated 653,000 MR procedures were performed at facilities nationwide. However, an estimated $26 \%$ of all women seeking an MR at facilities were turned away, and about one in 10 of those who had an MR were treated for complications. Nationally, the annual abortion rate was 18.2 per 1,000 women aged 15-44, and the MR rate was 18.3 per 1,000 women.

CONCLUSIONS: The incidence of induced abortion is the same as that of MR, which suggests considerable unsatisfied demand for the latter service. Furthermore, the high rates of complications from MRs highlight the need to improve the quality of clinical services. Increased access to contraceptives and MR services would help reduce rates of unplanned pregnancy and unsafe abortion.

International Perspectives on Sexual and Reproductive Health, 2012, 38(3):122-132, doi: 10.1363/3812212

Among the many developing countries where abortion is highly legally restricted, Bangladesh is unique in permitting the provision of menstrual regulation (MR) services as part of the government family planning program. MR procedures are generally performed using manual vacuum aspiration, with a maximum limit of 10 weeks after a woman's last menstrual period, and without a test to confirm pregnancy.* The MR program is considered to contribute significantly to protecting women's health, ${ }^{1}$ manual vacuum aspiration, which is recommended by the World Health Organization, ${ }^{2,3}$ has a very low rate of complications and mortality when performed by trained staff in hygienic conditions. ${ }^{4-6}$ However, unsafe induced abortions are still widely performed in Bangladesh.

The national rate of MRs and induced abortions combined was 28 per 1,000 women aged 15-44 in 1995 (based on indirect estimation techniques), ${ }^{7}$ the same rate as in South-central Asia in that year. ${ }^{\dagger 8}$ According to another study using a model-based approach, the combined MR and abortion rate in Bangladesh was in the range of 26-30 per 1,000 in the mid-1990s. ${ }^{9}$

*Family welfare visitors and paramedics may perform MR procedures up to eight weeks after the last menstrual period, and physicians may do so up to 10 weeks.

tThis regional estimate includes MRs and both legal and illegal abortions.
No national study on the incidence of MR and abortion has been conducted since the 1995 analysis. ${ }^{7}$ Yet in the past 15 years, notable changes have occurred in Bangladesh that may have affected access to MR services and women's and couples' motivation to resort to MR or abortion. Unmet need for contraception remained substantial at $12 \%$ in 2011 , after declining from $17 \%$ in $2007 . .^{10,11}$ In addition, contraceptive use increased relatively slowly from the mid-1990s until 2011: The percentage of currently married women aged 15-49 using any method increased from $49 \%$ to $61 \%$-an average annual increase of 0.8 percentage points. Although a majority of Bangladeshi couples who use contraceptives relied on modern methods in the past and continued to do so in 2011 (52\% of married women), most used the pill, the injectable or condoms (44\%), and only a small proportion used methods with very low failure rates, such as sterilization, the IUD and the implant (8\%). ${ }^{11}$ Clearly, unmet need for contraception, use of traditional methods (9\% in 2011), and reliance on short-term, reversible methods with relatively high risks of contraceptive failure and discontinuation are important factors contributing to unintended pregnancy.

Bangladesh has made significant progress in reducing maternal mortality over the last two decades: The maternal mortality ratio is estimated to have fallen from 871 


\begin{tabular}{|c|c|c|c|c|c|c|}
\hline Sector and facility type & $\begin{array}{l}\text { No. of facilities } \\
\text { in country }\end{array}$ & $\begin{array}{l}\text { No. of facilities in } \\
\text { sample districts }\end{array}$ & $\begin{array}{l}\text { Sampling fraction } \\
\text { within sample } \\
\text { districts (\%) }\end{array}$ & $\begin{array}{l}\text { No. of facilities } \\
\text { selected }\end{array}$ & $\begin{array}{l}\text { No. of facilities } \\
\text { interviewed }\end{array}$ & $\begin{array}{l}\text { Response rate } \\
(\%)\end{array}$ \\
\hline Total & 5,301 & 1,945 & 37 & 729 & 670 & 92 \\
\hline \multicolumn{7}{|l|}{ Public-sector facilities } \\
\hline Public medical college hospitals & 19 & $19^{*}$ & 100 & 19 & 15 & 79 \\
\hline Private medical college hospitals & 42 & $42^{*}$ & 100 & 42 & 39 & 93 \\
\hline District hospitals & 60 & 15 & 100 & 15 & 15 & 100 \\
\hline Upazila health complexes & 421 & 98 & 100 & 98 & 97 & 99 \\
\hline Mother and child welfare centers & 100 & 28 & 100 & 28 & 26 & 93 \\
\hline $\begin{array}{l}\text { Union health and family welfare } \\
\text { centers }\end{array}$ & 3,127 & 1,131 & 24 & 273 & 246 & 90 \\
\hline \multicolumn{7}{|l|}{ Private-sector clinics } \\
\hline Small (0-19 beds) & 1,235 & 419 & 33 & 138 & 134 & 97 \\
\hline Medium (20-49 beds) & 228 & 132 & 55 & 72 & 59 & 82 \\
\hline Large ( $\geq 50$ beds) & 69 & 61 & 72 & 44 & 39 & 89 \\
\hline
\end{tabular}

${ }^{*}$ All public and private medical college hospitals in the country were included. †Private medical college hospitals were grouped with public-sector facilities because they are similar to public medical college hospitals in terms of service provision.

deaths per 100,000 live births in 1990 to 337 per 100,000 in 2008. ${ }^{12}$ The two most recent maternal mortality surveys conducted by the government confirmed that a significant decline continued over the last decade. ${ }^{13,14}$ Results from a national survey in 2010 indicate that abortion accounted for about $1 \%$ of all maternal deaths. ${ }^{13}$ According to a study in the Matlab district, large reductions in abortion-related deaths occurred between 1976 and 2005; these reductions, along with investments in family planning and emergency obstetric care, accounted for a significant proportion of the overall decline in the maternal mortality ratio. ${ }^{15}$ The new estimates of MR and abortion incidence from the present study will allow researchers to further investigate the role of MR in the reduction in maternal mortality in Bangladesh.

It is important to know if provision of MR services in the country has deteriorated, remained stable or improved since 1995, and whether the role of those services (relative to that of abortion services) has changed. A situation analysis conducted in 2002 highlighted important barriers to obtaining MR services: distance to facility, unofficial fees, lack of privacy, unfavorable provider attitudes, inadequate infection prevention and nonobservance of protocols. ${ }^{16}$ Another study documented the particularly poor access of rural women to MR services. ${ }^{17}$ In addition, the failure to train adequate numbers of MR providers to replace retiring cohorts may have reduced access further in recent years. An in-depth study in 2011 indicated that these barriers continue to exist, forcing poor women to use informal providers for health care services, including abortion. $^{18}$

These concerns about possible declines in access to and quality of MR services are important reasons to collect new data on the incidence of MR and abortion (both safe and unsafe) to ensure that the reproductive health gains that Bangladesh has made in the past are not jeopardized. This study provides updated estimates of the incidence of MR and abortion in 2010 for Bangladesh and its six major divisions. We also discuss changes in these measures between 1995 and 2010 while acknowledging the limitations of data comparability; we examine broader demographic changes as well, including contraceptive use and unmet need for contraception.

\section{METHODS \\ Data Sources}

This study draws on three data collection efforts: a national survey of public- and private-sector health facilities that provide postabortion care and MR services; a survey of knowledgeable key informants; and compilation of data obtained from nongovernmental organizations (NGOs) on MR and postabortion care services provided by their clinics. The study design and protocols for the two surveys were based on prior research that developed a methodology for estimating abortion incidence (Abortion Incidence Complications Methodology or $\mathrm{AICM}^{19}$ ), and were adapted to the situation in Bangladesh. Questionnaires for both surveys were pretested in April 2010; the surveys were fielded from May to November 2010.

Other sources include Demographic and Health Survey (DHS) data sets for 1996-1997,20 1999-2000, $21004^{22}$ and $2007,{ }^{10}$ and preliminary results from the 2011 DHS. $^{11}$ These surveys provide information on contraceptive use, planning status of births and unmet need for contraception. The 2010 Household Income and Expenditure Survey $^{23}$ provides information on poverty level.

- Health Facilities Survey (HFS). All public and private health facilities (excluding NGO facilities for which statistics were separately compiled) considered likely to provide postabortion care or MR services were included in the sample frame. Using the most recent Ministry of Health lists of health facilities in Bangladesh, the 2008 Statistical Yearbook of Bangladesh, ${ }^{24}$ and information obtained from the Directorate General of Health Services and Directorate General of Family Planning, we identified a total of 5,301 facilities (Table 1). The government sector includes five 
main types of health facilities: medical college hospitals, ${ }^{*}$ district hospitals, upazila health complexes, mother and child welfare centers, and union health and family welfare centers (UH\&FWCs). The last facility type is staffed by family welfare visitors (FWVs) and paramedics and provides MR services but not postabortion care. Privatesector clinics-which account for $29 \%$ of all facilities-were divided into three categories based on bed count to ensure adequate representation of facilities of all sizes.

A stratified multistage sample design was used. Because of their large role in the treatment of postabortion care and MR cases, all public and private medical college hospitals were selected. For other categories of facilities, the sample was drawn from 16 districts randomly selected out of the 64 districts in Bangladesh. The master list of all facilities was organized by type and by district within each type. A proportion of each type was selected: Sample fractions were determined by the degree of importance of each facility type in providing postabortion care and MR services and on the absolute number of facilities of each type. Because district hospitals, upazila health complexes, and mother and child welfare centers are critical sources of treatment for abortion complications and the numbers of these facilities are relatively small, 100\% of each of these types in the 16 sample districts were included in the HFS sample. The sample fractions for the remaining facility types were $24 \%$ of UH\&FWCs, $33 \%$ of small private clinics, $55 \%$ of medium private clinics and $72 \%$ of large private clinics. Overall, 729 facilities were selected for the sample, representing $37 \%$ of the 1,945 facilities in the 16 sample districts. We successfully interviewed individuals at 670 facilities, for a response rate of $92 \%$.

At each selected facility, a senior staff member who was knowledgeable about the facility's provision of postabortion care and MR services was interviewed; in hospitals, the respondent was typically the chief of obstetrics and gynecology, while in smaller facilities it was typically the director or another senior staff member. Informants were asked whether their facilities provided treatment of abortion complications in an outpatient or inpatient setting; if treatment was provided, they were asked the number of outpatients and inpatients treated for complications of abortion (spontaneous and induced combined), in the average month and in the past month. Specifying these two time frames increases the likelihood of accurate recall and of capturing month-to-month variation. These numbers were averaged

*For the purposes of sampling and analysis, we grouped private- and public-sector medical college hospitals together, as they offer similar services.

tIn a small number of UH\&FWCs where more than one family welfare visitor or paramedic was interviewed, we assessed the data to determine whether they were answering individually or for the facility as a whole. In most cases, however, the additional person interviewed had not provided MR services.

¥These NGOs included the Reproductive Health Services Training and Education Programme, the Association for Prevention of Septic Abortion, Bangladesh, the Bangladesh Women's Health Coalition, the Family Planning Association of Bangladesh, the Urban Primary Health Care Project, Marie Stopes International and BRAC Bangladesh. and multiplied by 12 to produce an estimate for the calendar year. In addition, informants were asked to estimate how many of these cases were a result of complications from MR procedures: In the analysis, these cases were subtracted from the total number of abortion complications to avoid double counting. A similar method was used to gather data on the number of MR procedures. In the case of public medical college and district hospitals, which often have an NGO clinic on the premises providing MR services, data were collected only for services performed by the facility itself to ensure that NGO provision of these services was not double-counted. For most UH\&FWCs, one family welfare visitor was interviewed and asked to estimate the number of MR procedures performed by all FWVs and paramedics working at that facility, as well as the number that these personnel performed outside the facility (typically at their home or clients' homes). The sum of procedures performed inside and outside of each center by all staff yielded the total number of MRs provided by each facility. ${ }^{\dagger}$ Respondents at all facilities were also asked the number of women seeking an MR who had not been approved for the procedure for any reason in the past month.

The survey data were weighted to produce national estimates, taking into account a facility's probability of selection and facility response rates, by division and type. The weighting factor for a given category of facility is the inverse of the product of its sampling fraction and the response rate for its type and division. (For greater accuracy, weights were calculated on the basis of the proportion of beds rather than the proportion of facilities.)

- NGO provision of MR and postabortion services. We compiled data from the central offices of all the major NGOs providing MRs or postabortion care in Bangladesh ${ }^{\ddagger}$ on the number of MR procedures performed and the number of women treated for abortion complications in 2010, for each division, at all of their facilities.

- Health Professionals Survey (HPS). Using information gathered from program planners and other stakeholders, we prepared a list of health professionals who were known to be familiar with postabortion care and MR services, from all sectors and a wide range of professions, including clinicians, policymakers, researchers and reproductive health advocates. A purposive sample of 160 professionals was selected, and 151 were successfully interviewed. These professionals were drawn from all six divisions of Bangladesh, and from 33 of the 64 districts. The majority worked in urban areas, but we included professionals who were familiar with conditions in rural areas as well: Of the entire group, $41 \%$ had worked in rural areas for six months or longer in the five years prior to being interviewed.

The HPS was designed to elicit professionals' perceptions of various aspects of induced abortion and MR provision in Bangladesh. The survey provided the information necessary to calculate the multiplier, a factor used to estimate the total number of women who had induced abortions from the number of women who were treated for abortion complications. 
TABLE 2. Measures related to estimating the number of women treated in health facilities for complications of abortions, by type of abortion, all according to division

\begin{tabular}{|c|c|c|c|c|c|c|c|c|c|c|}
\hline \multirow[t]{2}{*}{ Division } & \multirow{2}{*}{$\begin{array}{l}\text { No. of women } \\
\text { aged 15-44 }\end{array}$} & \multirow{2}{*}{$\begin{array}{l}\text { No. of live } \\
\text { births }\end{array}$} & \multicolumn{3}{|c|}{ No. of women treated for } & \multirow{2}{*}{$\begin{array}{l}\text { No.treated for } \\
\text { induced abortion } \\
\text { complications } \\
\text { per } 1,000 \text { women }\end{array}$} & \multirow{2}{*}{$\begin{array}{l}\text { No. of safe } \\
\text { illegal } \\
\text { abortions* }\end{array}$} & \multicolumn{3}{|c|}{ Range of multipliers } \\
\hline & & & $\begin{array}{l}\text { All abortion- } \\
\text { related } \\
\text { complications }\end{array}$ & $\begin{array}{l}\text { Spontaneous } \\
\text { abortions }\end{array}$ & $\begin{array}{l}\text { Induced } \\
\text { abortions }\end{array}$ & & & Low & Medium & High \\
\hline Bangladesh & $35,601,229$ & $3,551,682$ & 280,453 & 49,086 & 231,367 & 6.5 & 74,615 & 1.9 & 2.5 & 3.0 \\
\hline Barisal & $2,136,760$ & 222,385 & 8,924 & 3,982 & 4,942 & 2.3 & 4,973 & 1.5 & 1.9 & 2.3 \\
\hline Chittagong & $6,576,957$ & 782,764 & 40,789 & 11,561 & 29,228 & 4.4 & 11,759 & 1.8 & 2.3 & 2.8 \\
\hline Dhaka & $11,112,599$ & $1,135,043$ & 74,107 & 13,239 & 60,868 & 5.5 & 25,788 & 2.3 & 2.9 & 3.6 \\
\hline Khulna & $4,503,456$ & 327,902 & 59,851 & 5,871 & 53,980 & 12.0 & 7,428 & 1.5 & 1.9 & 2.3 \\
\hline Rajshahi & $8,979,999$ & 775,913 & 75,738 & 9,889 & 65,849 & 7.3 & 21,165 & 2.1 & 2.7 & 3.2 \\
\hline Sylhet & $2,291,458$ & 307,675 & 21,044 & 4,544 & 16,500 & 7.2 & 3,502 & 1.9 & 2.3 & 2.8 \\
\hline
\end{tabular}

*Calculated as $14.9 \%$ of the reported (unadjusted) number of menstrual regulation procedures in public and private sectors (excluding nongovernmental organizations); see text for explanation. Note: Regions are as defined in early 2010; a new division (Rangpur) was subsequently created in Rajshahi.

\section{Estimating the Incidence of Menstrual Regulation}

According to data from the HFS survey and NGO providers, an estimated 500,800 MR procedures were reported in 2010. However, adjustments are needed for the following sources of undercount: Providers in public- and privatesector facilities are assumed to underreport MR services ${ }^{* 25}$ that do not follow regulations (e.g., those they provide outside of facilities, those in which the number of weeks past the last menstrual period is more than allowed or-in the case of public facilities-those for which they charge unofficial fees). UH\&FWCs are expected to have substantially higher levels of underreporting than higher-level publicsector facilities, where supervision of staff is usually closer, leaving less opportunity to charge fees or provide off-therecord services.

A 2004 study suggested that underreporting among all facilities was as high as $70 \% .{ }^{16}$ A recent small-scale inquiry in a district of seven upazilas and a population of two million-and that had a high level of assurance of confidentiality and long-standing relationships between interviewers and providers-also found that providers performed 70\% more MRs than they reported to the governmental health system. ${ }^{26}$ We expect that underreporting in the HFS was likely lower than that found in these studies (given that the HFS was not a government survey and respondents were assured that their information was confidential). Considering the high levels of underreporting documented by these two studies and the expected differentials in underreporting, we made the following conservative corrections for underreporting: $40 \%$ for UH\&FWCs, $25 \%$ for private clinics and 15\% for public clinics. After correcting for underreporting, we arrived at an adjusted total estimate of the number of MR procedures performed in Bangladesh in 2010 (23\% of which were derived from these adjustments).

\section{Estimating the Incidence of Induced Abortion}

The incidence of induced abortion was estimated by using the AICM, adapted to the context in Bangladesh. The estimate comprised three components-women treated for induced abortion complications, women who had had an unsafe induced abortion and needed treatment but did not obtain care at a health facility, and women who had had a safe illegal induced abortion. ${ }^{\dagger}$ Each component is discussed below. A small number of legal, safe abortions that may be taking place to save a woman's life were excluded from our analysis because of the lack of data. ${ }^{25}$

-Women treated for abortion complications. The total number of women treated for complications of spontaneous or induced abortion in 2010 was obtained from the HFS survey and NGO provider data-an estimated 280,500 women (Table 2), excluding 78,100 women treated for complications from MRs.

Because complications of induced and spontaneous abortion often are similar, and because restrictive abortion laws may lead to unwillingness to report complications of induced abortion, HFS respondents were not asked to provide separate estimates for each type of pregnancy loss. Instead, we employed an indirect estimation approach to estimate the number of patients with complications arising from each type. We used available data on the biological pattern of all spontaneous abortions (unrelated to hospitalization), established by clinical studies, ${ }^{27,28}$ to indirectly estimate the number of women who have miscarriages at 13-22 weeks' gestation; these women are assumed to require care at a health facility. ${ }^{\ddagger}$ These miscarriages are estimated to be $3.4 \%$ of all live births.

We estimated the total population of Bangladesh in 2010 using 2007 and 2011 estimates from the Bangladesh

*A 2010 study found substantial underreporting in records on MR services: Eleven percent of respondents believed that their own facility had inaccurate records and $20 \%$ said that MR records in general are inaccurate. ${ }^{25}$ Although the HFS did not use the MR records or statistics kept by facilities, our results support findings from other studies that surveybased data on MR numbers (including those from the HFS) are likely to be underreported.

tWe use the term "safe illegal abortion," but acknowledge that it would be more accurate to describe these as "low risk," as all clandestine illegal abortions necessarily carry some risk.

¥Women who miscarried in the first trimester are unlikely to have sought medical care from the surveyed facilities (i.e., hospitals and health centers), and more likely to have sought care from lower-level facilities or from trained or untrained providers who do not work at a facility. In addition, given that the World Health Organization classifies spontaneous losses at 22 or more weeks' gestation as fetal deaths, spontaneous abortion patients of this gestational age are excluded from the calculations. 
TABLE 3. Estimated number of menstrual regulation (MR) procedures, percentage distribution of MRs by type of provider and MR rate, all according to division

\begin{tabular}{|c|c|c|c|c|c|c|c|}
\hline \multirow[t]{2}{*}{ Division } & \multirow{2}{*}{$\begin{array}{l}\text { Total no. } \\
\text { of MRs }\end{array}$} & \multicolumn{2}{|c|}{ Public sector } & \multirow{2}{*}{$\begin{array}{l}\text { Private } \\
\text { clinics }\end{array}$} & \multirow{2}{*}{$\begin{array}{l}\text { NGO } \\
\text { providers }\end{array}$} & \multirow[t]{2}{*}{ Total } & \multirow{2}{*}{$\begin{array}{l}\text { No. of MRs per } 1,000 \\
\text { women aged } 15-44\end{array}$} \\
\hline & & UH\&FWCS & Other facilities* & & & & \\
\hline Bangladesh & 653,078 & 46.2 & 17.1 & 9.1 & 27.6 & 100.0 & 18.3 \\
\hline Barisal & 42,740 & 42.0 & 28.7 & 3.2 & 26.1 & 100.0 & 20.0 \\
\hline Chittagong & 99,494 & 42.3 & 19.4 & 3.4 & 34.9 & 100.0 & 15.1 \\
\hline Dhaka & 223,569 & 42.3 & 13.0 & 14.9 & 29.8 & 100.0 & 20.1 \\
\hline Khulna & 61,833 & 30.4 & 13.3 & 20.8 & 35.4 & 100.0 & 13.7 \\
\hline Rajshahi & 197,148 & 60.2 & 18.8 & 4.2 & 16.8 & 100.0 & 22.0 \\
\hline Sylhet & 28,294 & 33.7 & 19.6 & 2.0 & 44.7 & 100.0 & 12.3 \\
\hline
\end{tabular}

*Includes public and private medical college hospitals, district hospitals, upazila health complexes, and mother and child welfare centers. Notes: UH\&FWC= union health and family welfare center. $\mathrm{NGO}=$ nongovernmental organization.

Bureau of Statistics. ${ }^{29,30}$ Using the divisional distribution of women of reproductive age from the 2007 DHS $^{10}$ and the most recent age-specific population distribution, ${ }^{29}$ we calculated the number of women of reproductive age in each five-year age-group in 2010 for each division. ${ }^{29}$ The numbers of births in Bangladesh and in the six regions in 2010 were estimated by applying age-specific fertility rates from the 2007 DHS to the number of women in each age-group. According to these calculations, an estimated $3,551,700$ live births and 121,100 late spontaneous abortions $(0.0341 \times 3,551,682=121,112)$ occurred in 2010 in Bangladesh.

A further adjustment was needed because only a certain proportion of women who need treatment for complications of late spontaneous abortion have access to a health facility. We assumed that this proportion was equivalent to the HPS-based estimate of the proportion obtaining care in facilities for complications of induced abortion-41\% in Bangladesh as a whole. ${ }^{11}$ We therefore estimated that 49,100 women $(0.4053 \times 121,112=49,086)$ were treated in health facilities each year for complications of spontaneous abortion. Subtracting this number from the total postabortion care caseload yields an estimated 231,400 women treated for complications of unsafe induced abortion each year in all public, private and NGO facilities.

- Women with complications who did not receive treatment. This group was estimated using an adapted version of the AICM multiplier. The adapted multiplier allowed us to es- timate the number of women who had obtained unsafe induced abortions and experienced complications but did not obtain treatment. The more accessible abortion services are, the lower the multiplier, because more women who require treatment will receive it. We calculated these multipliers using HPS estimates of the proportion of women who had complications who received treatment. Because the conditions under which women obtain abortions vary greatly by socioeconomic status and place of residence, these questions were asked separately in the HPS about each of four socioeconomic subgroups (urban poor and nonpoor, and rural poor and nonpoor). Results were weighted by the relative size of the subgroups to arrive at national and regional multipliers. The multipliers ranged from 1.9 in Khulna and Barisal to 2.9 in Dhaka: These figures indicate that approximately one in two women who needed treatment for complications of induced abortions obtained treatment in health facilities in Khulna and Barisal, and approximately one in three did so in Dhaka.

Using HFS data, we calculated the 95\% confidence interval around the HFS postabortion care caseload, taking into account the complex sample design. We used the boundaries of this interval to define low and high estimates of the multipliers. For the country as a whole, the low, medium and high multipliers were thus estimated as 1.9, 2.5 and 3.0. While results based on the medium multiplier are recommended for general use, it is important to bear in mind that this is an approximate estimate within this range.

\begin{tabular}{|c|c|c|c|c|c|c|c|c|c|}
\hline \multirow[t]{2}{*}{ Division } & \multicolumn{3}{|c|}{ Total no. of induced abortions* } & \multicolumn{3}{|c|}{ Abortion rate† } & \multicolumn{3}{|c|}{ Abortion ratio $\neq$} \\
\hline & Low & Medium & High & Low & Medium & High & Low & Medium & High \\
\hline Bangladesh & 523,803 & 646,550 & 769,296 & 14.7 & 18.2 & 21.6 & 15 & 18 & 22 \\
\hline Barisal & 12,366 & 14,387 & 16,407 & 5.8 & 6.7 & 7.7 & 6 & 6 & 7 \\
\hline Chittagong & 64,759 & 79,241 & 93,724 & 9.8 & 12.0 & 14.3 & 8 & 10 & 12 \\
\hline Dhaka & 165,550 & 203,743 & 241,934 & 14.9 & 18.3 & 21.8 & 15 & 18 & 21 \\
\hline Khulna & 88,174 & 110,239 & 132,304 & 19.6 & 24.5 & 29.4 & 27 & 34 & 40 \\
\hline Rajshahi & 159,532 & 197,343 & 235,154 & 17.8 & 22.0 & 26.2 & 21 & 25 & 30 \\
\hline Sylhet & 33,422 & 41,597 & 49,773 & 14.6 & 18.2 & 21.7 & 11 & 14 & 16 \\
\hline
\end{tabular}

*Total number of induced abortions is the sum of three components: women treated for abortion complications in facilities, women with abortion complications who did not receive care in facilities and women who had safe illegal abortions. †Abortion rate is the number of abortions per 1,000 women aged

$15-44$. $¥$ Abortion ratio is the number of abortions per 100 live births. 
- Women who had safe illegal abortions. Because MR services are widely accessible up to 10 weeks after the last menstrual period and adequate data on MR incidence are available, we adapted the AICM approach to estimate the number of women who obtained safe illegal abortions. We anticipated that in the context of Bangladesh, women who are not approved when they seek an MR will be the primary group obtaining such abortions, as they are motivated and knowledgeable about clinics and trained providers. We therefore estimated the number of women obtaining safe illegal abortions as a proportion of the number of MRseeking clients whose requests were denied. Few studies have examined what women do after being refused an MR; however, an older study that followed up such MR clients found that $39 \%$ of them did try again, and about $80 \%$ of this group went to doctors and paramedics. ${ }^{31}$ From the HFS survey, we know that $26 \%$ of all women who sought an MR were turned away. We estimated that half of these women will then obtain safe illegal abortions (i.e., 13\%), and we assumed that this estimate included not only women who had sought and been refused MR services, but also some other women who obtained such abortions (e.g., women who had not sought MR services, regardless of the number of weeks since their last menstrual period). Thus, 15\%-that is, 13\% of all women seeking an MR, expressed as a percentage of reported MRs, or 0.1297/ $(1-0.1297)=0.149-$ of the reported (unadjusted) number of MRs represents the estimated number of safe illegal abortions, or 74,600. Nationally, the estimated total number of induced abortions (unsafe abortions and safe illegal abortions) is 646,600 (see Table 4).

\section{Estimating Unintended and Intended Pregnancies}

The sum of all live births, abortions and miscarriages (from intended and unintended pregnancies) yields the total number of pregnancies. To calculate unintended pregnancies nationally and by division, we summed the numbers of induced abortions, miscarriages attributable to unintended pregnancies, MRs and unplanned births; the last measure was derived by multiplying the proportion of unplanned births (mistimed or unwanted at the time of conception) reported in the 2007 DHS by the number of live births. To estimate the number of unintended pregnancies that end in miscarriage, we used a modelbased approach from clinical studies of pregnancy loss by gestational age: ${ }^{27,28}$ We applied the parameters from that model-pregnancy losses are estimated to be $20 \%$ of live births plus $10 \%$ of induced abortions-to the number of unplanned births. The number of planned pregnancies was calculated similarly, by summing planned births and miscarriages from intended pregnancies.

\section{RESULTS}

\section{Incidence of Menstrual Regulation}

An estimated 653,100 MR procedures were performed in Bangladesh in 2010 (Table 3). Nationally, the public sector accounted for almost two-thirds of all MR services;
TABLE 5. Abortion and menstrual regulation incidence, treatment rates and related demographic measures, 1995 and 2010

\begin{tabular}{|c|c|c|c|}
\hline Measure & 1995 & 2010 & $\%$ change \\
\hline \multicolumn{4}{|l|}{ Demographic measures } \\
\hline No. of women aged 15-44 & $26,318,400$ & $35,601,229$ & 35 \\
\hline No. of live births & $3,404,854$ & $3,551,682$ & 4 \\
\hline No.of pregnancies & $4,889,220$ & $5,691,608$ & 16 \\
\hline Pregnancy rate* & 185.8 & 159.9 & -14 \\
\hline No.of unintended pregnancies & $2,151,717$ & $2,630,774$ & 22 \\
\hline Unintended pregnancy rate* & 81.8 & 73.9 & -10 \\
\hline$\%$ of pregnancies unintended & 44.0 & 46.2 & 5 \\
\hline Total fertility rate $\dagger$ & 3.3 & 2.7 & -17 \\
\hline Wanted total fertility rate $†$ & 2.1 & 1.9 & -10 \\
\hline \multicolumn{4}{|c|}{ Treatment/incidence rates } \\
\hline \multicolumn{4}{|c|}{ Treatment rate for MR complications* } \\
\hline Public facilities $\neq$ & 0.7 & 1.1 & 53 \\
\hline Private facilities & na & 1.1 & na \\
\hline \multicolumn{4}{|c|}{ Treatment rate for abortion complications ${ }^{*}, \S$} \\
\hline Public facilities $\neq$ & 2.7 & 4.3 & 59 \\
\hline Private/NGO facilities & na & 3.6 & na \\
\hline Menstrual regulation rate ${ }^{*}$ & 17.8 & 18.3 & 3 \\
\hline Abortion rate* & 10.0 & 18.2 & 82 \\
\hline
\end{tabular}

*Per 1,000 women aged 15-44. +Based on the 1996-1997 and 2007 DHS, respectively. \#Includes private medical college hospitals. §Includes induced and spontaneous abortions. Notes: MR=menstrual regulation. $\mathrm{NGO}=$ nongovernmental organization. na=not available. Sources: 1995-reference 7 and unpublished estimates from the present study. $\mathbf{2 0 1 0}$ - the present study unless otherwise indicated.

UH\&FWCs were responsible for almost half of all procedures, and more than two-thirds of public-sector services. Nongovernmental providers accounted for a little more than one-quarter of MR services, and private clinics for close to one-tenth.

There were substantial variations in the relative importance of the different categories of MR providers across the six divisions. The public sector accounted for $63 \%$ of services nationally, but its share was larger in Barisal and Rajshahi (71-79\%) and smaller in Dhaka, Khulna and Sylhet (44-55\%). Conversely, private clinics accounted for 9\% of services for the country as a whole; their contribution was more important in Dhaka and Khulna (15-21\%), but less important in the other four divisions (2-4\%). NGO facilities accounted for $45 \%$ of MR services in Sylhet and 17\% in Rajshahi, compared with $28 \%$ nationally.

Nationally, $18 \mathrm{MR}$ procedures were performed per 1,000 women of reproductive age in 2010. Across divisions, the MR rate ranged from 12 to 22 per 1,000 women. The rate was substantially below average in Sylhet and Khulna (12 and 14 , respectively) and above average in Rajshahi (22).

\section{Incidence of Induced Abortion}

Estimates of the number of induced abortions were calculated separately from those of MR procedures. We focus on the medium estimate as representing the most likely situation.

An estimated 646,600 induced abortions were performed in Bangladesh in 2010, for an annual rate of 18 abortions per 1,000 women aged 15-44 (Table 4). The abortion rate was nearly identical to the national average in Dhaka and Sylhet, higher than average in Rajshahi and Khulna (22 and 25, respectively), lower than average in Chittagong (12) and exceptionally low in Barisal (7). The 
FIGURE 1. Percentage distribution of pregnancies, by outcome and intention, Bangladesh, 1995 and 2010

1995

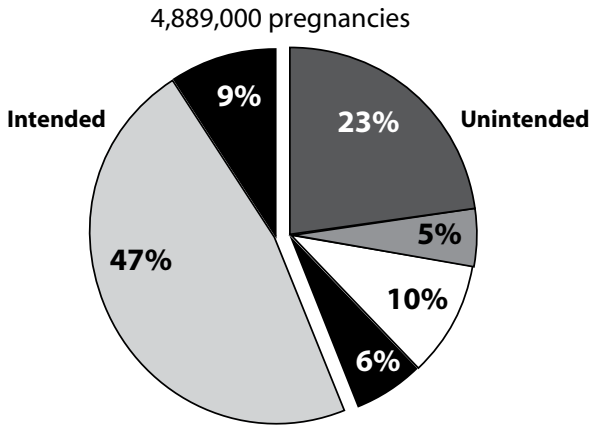

2010

$5,762,000$ pregnancies
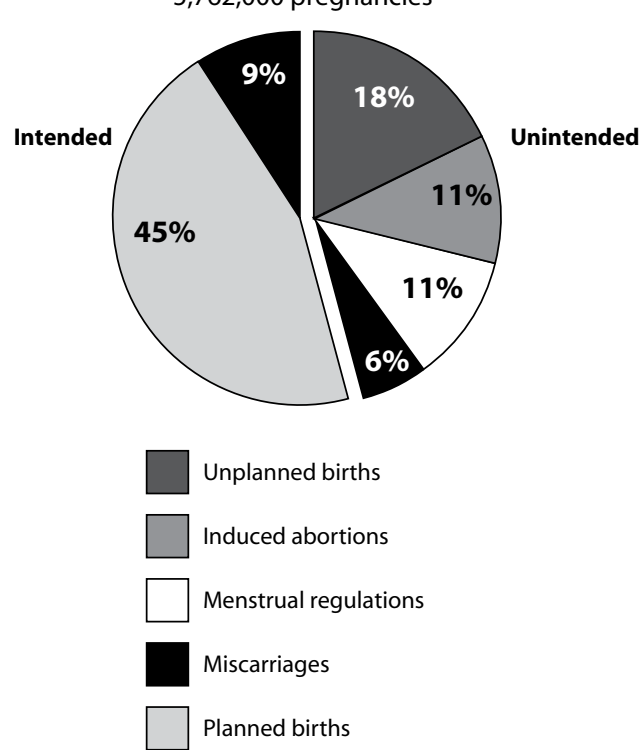

low rate in Barisal may reflect an undercount of women receiving treatment for postabortion complications in the HFS or a lower propensity to obtain abortion services in this division.

Bangladesh is unusual in having the private and public sectors play equal roles in the provision of postabortion care: Data from the HFS show that each sector accounted for about half of all women treated for abortion-related complications in 2010. Notably, small private clinics with fewer than 20 beds accounted for two-thirds of privatesector postabortion care (not shown).

The ratio of induced abortions to live births was 18 per 100 nationally; Khulna and Rajshahi had the highest abortion ratios (34 and 25, respectively), while Barisal, Chittagong and Sylhet had the lowest (6-14). This measure is an indicator of the likelihood that, once pregnant, a woman will have an induced abortion: The national ratio of 18 per 100 births means that approximately one woman has an induced abortion for every five who give birth. It is also useful to calculate a combined ratio of MR procedures and induced abortions. The combined ratio of 37 per 100 live births indicates that about two pregnancies are ended for every five that result in live births; this combined ratio for Bangladesh is higher than the estimated abortion ratio for South-central Asia in 2008 (26 per 100). ${ }^{32}$ Combining the national numbers of induced abortions and MR procedures shows that induced abortions represented $50 \%$ of this total.

\section{Change in Morbidity, MRs and Induced Abortions}

Comparison of results from the 1995 study with the estimates for 2010 yields insights into change in the safety of MR and induced abortion services, as well as the incidence of these procedures. However, given differences in both sample coverage and methodology, care must be taken in making comparisons. Because the 2010 sample design included comprehensive coverage of the private sector, while the 1995 study did not, we limit comparisons to public-sector treatment rates for complications resulting from MRs and induced abortions. The treatment rate for MR complications was 53\% higher in 2010 than in 1995 ( 1.1 vs. 0.7 women per 1,000 ), while that for abortion complications rose by $59 \%$ (4.3 vs. $2.7-$ Table 5 , page 127 ). It is possible that most, if not all, of this increase is due to improvements in access to health services, reflecting existing demand for pregnancy-related care. For example, the proportion of women delivering in health facilities increased manyfold during this period-from 4\% in 1996-199720 to $15 \%$ in $2007^{10}$ and to $29 \%$ in 2011 (not shown). ${ }^{11}$

While the absolute number of MRs increased by 39\% over this 15-year period, ${ }^{7}$ the MR rate increased only slightly, by an estimated 3\% (from 17.8 to 18.3 MRs per 1,000 women-Table 5), indicating that much of the absolute increase reflects the growing population of women aged 15-44 (which increased by 35\% during this period). Furthermore, the earlier study used a different approach in estimating the number of MRs in 1995: It projected forward from a 1987 study that had estimated MRs based on average caseloads reported by MR providers. The current study used a more robust approach; however, because of the widely recognized and extensive underreporting by both public and private providers, adjustments were made, and this introduced a further element of uncertainty. Overall, given differences in methodology, we cannot determine whether there has been a true change in the MR rate between 1995 and 2010.

Over this same period, the induced abortion rate appears to have increased by $82 \%$ (from 10.0 to 18.2 abortions per 1,000 women). It is likely that much of this increase is spurious. In comparison with the 2010 rate, the 1995 rate is likely to be underestimated, for two reasons: First, unlike the 1995 HFS, the 2010 HFS had nationally representative coverage of postabortion care provision in the private sector; and second, the 1995 multiplier likely overestimated access to postabortion services-health professionals estimated that $54 \%$ of women with complications obtained facility-based care, but at the time only $4 \%$ of women delivered in facilities. ${ }^{20}$ We conclude that 


\begin{tabular}{|c|c|c|c|c|c|c|c|c|c|c|c|c|c|c|c|}
\hline \multirow[t]{2}{*}{ Division } & \multicolumn{5}{|c|}{ Modern method } & \multicolumn{5}{|c|}{ Traditional method } & \multicolumn{5}{|c|}{ Unmet need } \\
\hline & $\begin{array}{l}1996- \\
1997\end{array}$ & $\begin{array}{l}1999- \\
2000\end{array}$ & 2004 & 2007 & 2011 & $\begin{array}{l}1996- \\
1997\end{array}$ & $\begin{array}{l}1999- \\
2000\end{array}$ & 2004 & 2007 & 2011 & $\begin{array}{l}1996- \\
1997\end{array}$ & $\begin{array}{l}1999- \\
2000\end{array}$ & 2004 & 2007 & 2011 \\
\hline Bangladesh & 42 & 43 & 47 & 48 & 52 & 8 & 10 & 11 & 8 & 9 & 16 & 15 & 11 & 17 & 12 \\
\hline Barisal & 41 & 46 & 43 & 47 & 55 & 8 & 14 & 12 & 9 & 10 & 18 & 15 & 13 & 20 & 10 \\
\hline Chittagong & 31 & 35 & 37 & 38 & 45 & 6 & 9 & 10 & 6 & 7 & 21 & 20 & 17 & 23 & 19 \\
\hline Dhaka & 42 & 42 & 49 & 48 & 51 & 8 & 12 & 11 & 9 & 10 & 17 & 16 & 11 & 18 & 11 \\
\hline Khulna & 51 & 51 & 51 & 53 & 56 & 11 & 13 & 13 & 10 & 11 & 11 & 11 & 8 & 12 & 8 \\
\hline Rajshahi* & 51 & 51 & 58 & 57 & 58 & 8 & 8 & 11 & 9 & 9 & 11 & 13 & 7 & 12 & 9 \\
\hline Sylhet & 16 & 25 & 22 & 25 & 35 & 4 & 9 & 10 & 7 & 10 & 21 & 22 & 21 & 26 & 16 \\
\hline
\end{tabular}

*In early 2010, a new division (Rangpur) was created in Rajshahi.Contraceptive use and unmet need in Rangpur are not included here, but proportions were similar to those shown for Rajshahi.Sources: 1996-1997—reference 20.1999-2000—reference 21.2004-reference 22. 2007-reference 10. 2011 reference 11.

the large increase in the induced abortion rate is mostly due to better measurement in 2010. Even though the rate may have increased, the size of the increase is likely much smaller than these two figures indicate.

\section{Morbidity Related to Abortion and MR Procedures}

The overall rate of treatment for induced abortion complications was quite high in 2010: An estimated 6.5 women per 1,000 aged 15-44 were treated each year (see Table 2), a rate comparable with those in a number of other developing countries where abortion is highly legally restricted and MR services do not exist. ${ }^{33}$ In addition, an estimated 2.2 women per 1,000 were treated in 2010 for complications from MR procedures that were presumably unsafe (see Table 5). This means that about $12 \%$ of women who had an MR experienced and were treated for medical complications (not shown). This is a minimum estimate because some women in this situation would not have obtained treatment. This rate is much higher than that found when the procedure is performed by trained personnel in hygienic settings, ${ }^{* 4-6}$ and is an indicator of the extent to which unsafe MR is taking place.

\section{Change in Unintended Pregnancy and Contraceptive Behavior}

The incidence of induced abortion and MR, and any changes in these measures over time, must be understood in the context of unintended pregnancy, fertility, contraceptive use and unmet need for family planning. Nationally, the overall pregnancy rate in 2010 was an estimated 160 pregnancies per 1,000 women of reproductive age, and the unintended pregnancy rate was 74 (see Table 5).

Among all pregnancies, the proportion that was unintended appears to have increased slightly between 1995 and 2010 (from 44\% to 46\%). However, given the likelihood that induced abortions were underestimated in 1995, this small increase is probably spurious. In 2010, induced abortions and MRs each accounted for more than one in 10 of all pregnancies, and together constituted about half of all unintended pregnancies (Figure 1). The proportion of pregnancies resulting in unplanned births declined moderately between 1995 and 2010 (from 23\% to $18 \%$ ). The overall pregnancy rate fell over this 15 -year period, from 186 to 160 pregnancies per 1,000 women (a decline of 14\%); the unintended pregnancy rate also fell, but at a slower pace (from 82 to 74 pregnancies per 1,000 women, a decrease of 10\%-see Table 5).

The prevalence of modern contraceptive use was already moderately high in 1996-1997 among married women (42\%), and it increased to 52\% by 2011 (Table 6). The proportion of married women using traditional methods, which have high failure rates, remained at $8-11 \%$ over this period. Method discontinuation remained common, but declined over the period 2007-2011: According to the 2011 DHS, 36\% of married women using methods other than female sterilization discontinued use within 12 months, a decrease from levels of $49 \%$ and $57 \%$ in the 2004 and 2007 DHS data sets, respectively. ${ }^{10}$ The proportion of married women with an unmet need for contraception, ${ }^{\dagger}$ which had fluctuated between 1996-1997 and 2007 with no clear trend, fell from 17\% to $12 \%$ between 2007 and 2011.

\section{DISCUSSION}

This study presents updated information on the incidence of induced abortion and MR in Bangladesh. By comparison with the only previous national study, conducted in 1995, the MR rate in 2010 is essentially unchanged. After accounting for improved measurement of abortion incidence, the induced abortion rate has also likely changed little over the past 15 years. Combining the MR and abortion rates to yield an estimate of the overall pregnancy termination rate shows that this rate in Bangladesh (37 per 1,000 women aged 15-44) is higher than the equivalent rate for South-central Asia in 2008 (26 per 1,000), but similar to that for Southeastern Asia (36 per 1,000). ${ }^{34}$

The unintended pregnancy rate in Bangladesh in 2010

*In a randomized controlled equivalence trial of first-trimester manual vacuum aspirations performed by midlevel providers and doctors, complication rates were $0-1.4 \%$ in South Africa and $1.2-1.4 \%$ in Vietnam. ${ }^{5}$

tWomen are considered to have an unmet need for contraception if they are fecund and married, are not using any contraceptive method, and do not want a child in the next two years or ever. 
is higher than those for South-central Asia and Southeastern Asia in 2008 (74 per 1,000 women vs. 56 and 66 per 1,000, respectively). ${ }^{35}$ These data highlight the need for better contraceptive services in Bangladesh. Women's use of induced abortion and menstrual regulation-which together account for about half of all unintended pregnancies-is a further indication of the need to address barriers to women obtaining and using accurate contraceptive information and quality services.

Although the use of modern contraceptive methods among married women increased from 42\% in 1996-1997 to $52 \%$ in 2011 , some aspects of method use contributed to unintended pregnancy: Nine percent of married women used traditional methods in 2011, 12\% used no method but did not want a child soon, and more than $80 \%$ of modern method users were using methods (e.g., condoms, the pill and the injectable) that had higher failure and discontinuation rates than the most effective methods (i.e., the IUD, the implant and sterilization). ${ }^{11,36}$ The increase in modern method use between 2007 and 2011, coming after a few years of no growth in such use, supports the value of investing in improving contraceptive services.

The availability of safe MR services from a range of providers-public, private and nongovernmental-is an important contributor to improvement in women's reproductive health in Bangladesh. MR services were first offered in the 1970s, and service provision capacity increased until the mid-1990s. However, it appears that in recent years the training of new family welfare visitors has been inadequate to replace retiring cohorts, and even more so to increase the numbers of providers overall. Findings from this study point to large gaps in the reach and coverage of MR services, as well as the quality of these services: About onethird of all facilities that could provide MRs lack trained staff or the necessary equipment. ${ }^{37}$ In addition, the high rate of complications indicates that some providers have inadequate training or experience, and some of the reasons given for turning away women who are seeking an MR (e.g., having no children, young age, being unmarried or lacking husband's consent) suggest that providers are imposing their personal values in refusing women a service to which they are entitled. ${ }^{37}$

The overall rate of complications from unsafe MR services is of concern. Manual vacuum aspiration procedures performed by trained staff in hygienic facilities should have an extremely low rate of complications. ${ }^{4-6}$ More research is needed to document the type and severity of MR complications, and to identify whether certain categories of providers or facilities have higher complication rates. Fluctuation in funding for training, equipment and supplies, especially over the past decade, may have contributed to a decline in the quality of MR services. ${ }^{10}$

About $40 \%$ of women who needed care for postabortion complications actually obtained care at facilities, which indicates a crucial need for improved provision of postabortion care, particularly for poor or rural women, who are estimated to have the highest probabilities of experiencing complications. ${ }^{38}$ Bangladesh is unusual in having the private sector play as great a role as the public sector in the provision of such care. In contrast, the public sector was responsible for nearly two-thirds of all MRs provided in 2010 and NGOs accounted for one-quarter, with the private sector accounting for the remainder. These findings suggest the importance of monitoring the quality of postabortion care in the private as well as the public sector. The prevalence of unsafe abortion underscores the need for greater efforts to educate women and the general public about the availability of MR services, sources for these services and requirements regarding the maximum number of weeks since the last menstrual period.

\section{Limitations}

The methodological approach and data used in this study have some limitations. The calculation of the number of women treated for spontaneous abortions in facilities in Bangladesh is based on assumptions from clinical studies conducted in the 1980s in the developed world. Even though these biological patterns are relatively stable, they may be somewhat different in Bangladesh and may have changed over the past 25 years.

Given the lack of empirical data, the information on which multipliers are based-the proportion of women having an unsafe induced abortion who need treatment but do not obtain care at a health facility-relies on key informants' perceptions. In addition, the facility-based data have a margin of error, both because they rely on estimates and because they are based on a sample survey, albeit one that was designed to be nationally representative. Although questions to HFS respondents distinguished clearly between complications resulting from MR procedures and those from unsafe abortions, if some of the latter complications were mischaracterized as MR complications, then the reported treatment rate for MR complications would be somewhat overestimated and that for postabortion complications would be underestimated.

Finally, our modified AICM method may underestimate the number of safe illegal abortions performed in the country: If this is the case, the abortion rate in Bangladesh would be higher than the one estimated in this article. Data on the extent of underreporting of MR services are scarce, although it is known to be common. As a result, the factors we used to adjust for underreporting are approximate figures only, and in fact may be somewhat conservative as well.

\section{Conclusions}

Improvements in MR services are an important means of reducing the incidence of induced abortions, which for the most part in Bangladesh are unsafe procedures that can lead to serious health complications. Studies have pointed to a number of reasons why women do not use existing MR services: high cost, lack of confidentiality, inconvenient hours and location of services, and an actual or perceived poor quality of care. ${ }^{16,39-41}$ In addition, the 2007 DHS 
found that $19 \%$ of married women did not know that MR services are permitted in Bangladesh. ${ }^{10}$ The fact that MR is permitted up to only 8-10 weeks since the last menstrual period (depending on the provider) means that many women will not be able to obtain services because their pregnancy is beyond these limits. In 2010, an estimated $26 \%$ of all women seeking MR services were turned down, and only $57 \%$ of facilities that would be expected to provide MR services actually did so. ${ }^{37}$ These findings point to areas in which improvements in the quality and availability of MR services are needed. Such improvements would have a substantial impact in reducing unsafe abortion, and should receive priority from the Bangladesh government and from the wide range of stakeholders-advocates, providers, policymakers and program planners-who are concerned with improving women's health.

\section{REFERENCES}

1. Amin S, Menstrual regulation in Bangladesh, in: Basu AM, ed., The Sociocultural and Political Aspects of Abortion, Westport, CT, USA: Praeger, 2003, pp. 153-166.

2. World Health Organization (WHO), Safe Abortion: Technical and Policy Guidance for Health Systems, Geneva: WHO, 2003.

3. WHO, Safe Abortion: Technical and Policy Guidance for Health Systems, second ed., Geneva: WHO, 2012.

4. Goldberg AB et al., Manual versus electric vacuum aspiration for early first-trimester abortion: a controlled study of complication rates, Obstetrics \& Gynecology, 2004, 103(1):101-107.

5. Warriner IK et al., Rates of complication in first-trimester manual vacuum aspiration abortion done by doctors and mid-level providers in South Africa and Vietnam: a randomised controlled equivalence trial, Lancet, 2006, 368(9551):1965-1972.

6 . Wen J et al., Manual versus electric vacuum aspiration for firsttrimester abortion: a systematic review, BJOG, 2008, 115(1):5-13.

7. Singh S et al., Estimating the level of abortion in the Philippines and Bangladesh, International Family Planning Perspectives, 1997, 23(3): $100-107 \& 144$.

8. Henshaw SK, Singh S and Haas T, The incidence of abortion worldwide, International Family Planning Perspectives, 1999, 25(Suppl.):S30S38.

9. Johnston HB and Westoff C, Examples of model-based approaches to estimating abortion, in: Singh S, Remez L and Tartaglione A, eds., Methodologies for Estimating Abortion Incidence and Abortion-Related Morbidity, New York: Guttmacher Institute; and Paris: International Union for the Scientific Study of Population, 2010, pp. 49-62.

10. National Institute of Population Research and Training (NIPORT), Mitra and Associates, and Macro International, Bangladesh Demographic and Health Survey, 2007, Dhaka, Bangladesh: NIPORT and Mitra and Associates; and Calverton, MD, USA: Macro International, 2009.

11. NIPORT, Mitra and Associates, and ICF International, Bangladesh Demographic and Health Survey, 2011: Preliminary Report, Dhaka, Bangladesh: NIPORT and Mitra and Associates; and Calverton, MD, USA: ICF International, 2012

12. WHO et al., Trends in Maternal Mortality: 1990 to 2008, Geneva: WHO, 2010

13. NIPORT, Bangladesh Maternal Mortality and Health Care Survey 2010: Summary of Key Findings and Implications, Dhaka, Bangladesh: NIPORT, 2011.

14. NIPORT et al., Bangladesh Maternal Health Services and Mortality Survey, 2001, Dhaka, Bangladesh: NIPORT, 2003.

15. Chowdhury ME et al., Causes of maternal mortality decline in Matlab, Bangladesh, Journal of Health, Population, and Nutrition, 2009, 27(2):108-123.
16. Chowdhury SNM and Moni D, A situation analysis of the menstrual regulation programme in Bangladesh, Reproductive Health Matters, 2004, 12(24, Suppl.):95-104.

17. Ahmed $S$ et al., Induced abortion: What's happening in rural Bangladesh, Reproductive Health Matters, 1999, 7(14):19-29.

18. Rashid SF, Akram O and Standing H, The sexual and reproductive health care market in Bangladesh: Where do poor women go? Reproductive Health Matters, 2011, 19(37):21-31.

19. Singh S, Prada E and Juarez F, The abortion incidence complications method: a quantitative technique, in: Singh S, Remez L and Tartaglione A, eds., Methodologies for Estimating Abortion Incidence and Abortion-Related Morbidity, New York: Guttmacher Institute; and Paris: International Union for the Scientific Study of Population, 2010, pp. 71-97.

20. Mitra S et al., Bangladesh Demographic and Health Survey, 19961997, Dhaka, Bangladesh: NIPORT and Mitra and Associates; and Calverton, MD, USA: Macro International, 1997.

21. NIPORT, Mitra and Associates, and ORC Macro, Bangladesh Demographic and Health Survey, 1999-2000, Dhaka, Bangladesh: NIPORT and Mitra and Associates; and Calverton, MD, USA: ORC Macro, 2001.

22. NIPORT, Mitra and Associates, and ORC Macro, Bangladesh Demographic and Health Survey, 2004, Dhaka, Bangladesh: NIPORT and Mitra and Associates; and Calverton, MD, USA: ORC Macro, 2005.

23. Bangladesh Bureau of Statistics (BBS), Report of the Household Income and Expenditure Survey, 2010, Dhaka: BBS, 2012.

24. BBS, 2008 Statistical Yearbook of Bangladesh, Dhaka: BBS, 2009.

25. Huda F et al., Strengthening Health System Capacity to Monitor and Evaluate Programmes Targeted at Reducing Abortion-Related Maternal Mortality, Dhaka: International Centre for Diarrhoeal Disease Research, Bangladesh, 2010

26. Unpublished data from Bangladesh Association for Prevention of Septic Abortion (BAPSA), Dhaka, Bangladesh, 2012

27. Bongaarts J and Potter R, Fertility, Biology and Behavior: An Analysis of the Proximate Determinants, New York: Academic Press, 1983.

28. Harlap S, Shiono PH and Ramcharan S, A life table of spontaneous abortions and the effects of age, parity, and other variables, in: Porter $\mathrm{IH}$ and Hook EB, eds., Human Embryonic and Fetal Death, New York: Academic Press, 1980, pp. 145-158.

29. BBS, Sample Vital Registration System, 2007, <http://www.bbs.gov. bd/PageReportLists.aspx?PARENTKEY=51>, accessed Mar. 1, 2011.

30. BBS, Bangladesh population clock, 2012, <www.bbs.gov.bd>, accessed Mar. 1, 2011

31. Kamal G and Begum S, Study on Intervention Necessary for Preventing Rejection of MR Clients, Dhaka: BAPSA, 1990

32. Sedgh G, Guttmacher Institute, New York, personal communication, Apr. 26, 2012.

33. Singh S, Hospital admissions resulting from unsafe abortion: estimates from 13 developing countries, Lancet, 2006, 368(9550):18871892.

34. Sedgh $G$ et al., Induced abortion: incidence and trends worldwide from 1995 to 2008, Lancet, 2012, 379(9816):625-632.

35. Singh S, Sedgh G and Hussain R, Unintended pregnancy: worldwide levels, trends, and outcomes, Studies in Family Planning, 2010, 4l(4):241-250.

36. Hatcher R et al., Contraceptive Technology, rev. 20th ed., Atlanta, GA, USA: Bridging the Gap Foundation, 2011.

37. Hossain A et al., Menstrual Regulation, Unsafe Abortion and Maternal Health in Bangladesh, New York: Guttmacher Institute, 2012, forthcoming.

38. Unpublished data from the 2010 Guttmacher Health Professionals Survey (Bangladesh).

39. Hashemi A, Rashid S and Rashid M, Where do women go and why? Understanding the barriers to safe MR services in Bangladesh, 
unpublished report, Dhaka, Bangladesh: James P. Grant School of Public Health, BRAC University, 2012

40. Caldwell B et al., Pregnancy termination in a rural subdistrict of Bangladesh: a microstudy, International Family Planning Perspectives, 1999, 25(1):34-37\& 43 .

41. Johnston $\mathrm{H}$ et al., Scaled up and marginalized: a review of Bangladesh's menstrual regulation programme and its impact, in: Blas E, Sommerfeld J and Kurup A, eds., Social Determinants Approaches to Public Health: From Concept to Practice, Geneva: WHO, 2011.

\section{RESUMEN}

Contexto: El gobierno de Bangladesh tiene la singularidad de incluir los servicios de regulación menstrual (RM) como parte de su programa de planificación familiar, a pesar de que la ley en cuanto al aborto es altamente restrictiva. Las únicas estimaciones nacionales disponibles de RM y aborto inducido provienen de un estudio realizado en 1995, por lo que se necesita información actualizada para dar soporte a las politicas y programas relacionados con la prestación de RM y servicios relacionados de salud reproductiva.

Métodos: En 2010 se condujeron una encuesta con una muestra representativa a nivel nacional de 670 instituciones de salud que proveen RM y servicios de atención postaborto, y otra de 151 profesionales conocedores del tema. También se compilaron estadísticas de los servicios de RM proporcionados por las organizaciones no gubernamentales. Se aplicaron técnicas de estimación indirecta para calcular la incidencia y las tasas de ambos, las RM y los abortos inducidos.

Resultados: Se estima que en 2010 se realizaron unos 647,000 abortos en Bangladesh; y 231,400 mujeres recibieron tratamiento por las complicaciones derivadas de esos abortos. Además, se realizaron unos 653,000 procedimientos de $R M$ en instituciones en el país. Sin embargo, se estima que 26\% del total de mujeres que solicitaron una RM en las instituciones fueron rechazadas; y cerca de una de cada 10 mujeres que tuvieron una RM fueron tratadas por complicaciones relacionadas. A nivel nacional, la tasa anual de aborto fue de 18.2 por 1,000 mujeres en edades de 15-44 y la tasa de RM fue de 18.3 por 1,000 mujeres.

Conclusiones: La incidencia del aborto inducido es la misma que la de RM, lo que sugiere una considerable demanda insatisfecha de este último servicio. Además, la alta tasa de complicaciones de RM destaca la necesidad de mejorar la calidad de los servicios clínicos. Un mayor acceso a los anticonceptivos y a los servicios de RM ayudaría a reducir las tasas de embarazos no planeados y del aborto inseguro.

\section{RÉSUMÉ}

Contexte: Le Bangladesh est unique en ce qu'il inclut les services de régulation menstruelle (RM) dans son programme national de la planification familiale, en dépit d'une législation fortement restrictive de l'avortement. Les seules estimations nationales d'incidence de la RM et de l'avortement remontent à une étude menée en 1995. Leur mise à jour est nécessaire à la documentation des politiques et programmes relatifs à la prestation de la RM et des services de santé génésique associés. Méthodes: Des enquêtes ont été menées en 2010 auprès d'un échantillon nationalement représentatif de 670 établissements de santé prestataires de services de RM et de soins après avortement et de 151 professionnels informés sur la question et les statistiques de prestation RM des organisations non gouvernementales ont été compilées. L'incidence et les taux de RM et d'avortement provoqué ont été calculés selon les techniques d'estimation indirecte.

Résultats: On estime à 647.000 le nombre d'avortements provoqués au Bangladesh en 2010; 231.400 femmes ont été traitées pour cause de complications de ces avortements. On estime de plus à 653.000 le nombre de procédures de RM pratiquées dans les établissements du pays. Sur l'ensemble des femmes en quête de RM, environ 26\% ont cependant été refusées dans les établissements de santé et environ 10\% de celles admises ont été traitées pour cause de complications. À l'échelle nationale, le taux d'avortement annuel est de 18,2 pour mille femmes âgées de 15 à 44 ans et le taux de RM, de 18,3 pour mille.

Conclusions: L'incidence de l'avortement provoqué est égale à celle de la RM, laissant entendre une demande non satisfaite considérable de ce dernier service. De plus, les hauts taux de complications de la RM soulignent le besoin d'amélioration de la qualité des services cliniques. Un accès accru à la contraception et aux services de RM permettrait de réduire les taux de grossesse non planifiée et d'avortement non médicalisé.

\section{Acknowledgments}

This research was supported by the Dutch Ministry of Foreign Affairs and the United Kingdom Department for International Development. The authors thank the Directorate General of Family Planning and the Directorate General of Health, Government of the People's Republic of Bangladesh, for their support and approval of the study. We are also grateful to Halida Hanum Akhter, Akinrinola Bankole, Patricia Donovan, Fátima Juarez, Lisa Remez and Gustavo Suárez for comments on early versions of this article, and to Anuradha Hashemi and Sabina Rashid for advice regarding estimates. The authors acknowledge the fieldwork team for their indispensable contributions in conducting the surveys, and are grateful to members of the Project Advisory Panel in Bangladesh for their valuable guidance and input throughout the project.

Author contact:ssingh@guttmacher.org 